3 Research S Quare

\title{
Evaluation and improvement of the emergency capacity of medical staff for COVID-19: A cross-sectional study in China
}

\author{
Shu-Xiao Hu \\ Xi'an Jiaotong University School of Public Policy and Administration \\ Chang-Fu Chen \\ Xi'an Jiaotong University School of Public Policy and Administration \\ Qing Liu ( $\square$ emma1845@163.com ) \\ Xi'an Jiaotong University https://orcid.org/0000-0001-9968-5668 \\ Gao-Fei Zhang \\ Xi'an Jiaotong University School of Public Policy and Administration \\ Hua-Lin Cheng \\ Xi'an Jiaotong University School of Public Policy and Administration \\ Yan-Xin Zhang \\ Xi'an Jiaotong University School of Public Policy and Administration
}

\section{Research article}

Keywords: emergency capacity, medical staff, COVID-19

Posted Date: January 19th, 2021

DOI: https://doi.org/10.21203/rs.3.rs-56429/v2

License: (c) (1) This work is licensed under a Creative Commons Attribution 4.0 International License. Read Full License 


\section{Abstract}

Background: Coronavirus disease 2019 (COVID-19) has spread to 216 countries and territories around the world. Most studies on response to public health emergencies, focus on health systems, local governments or medical organizations, but fewer studies focus on individuals. However, medical staff are the core strength for responding to public health emergencies. The aims of this study are to investigate the status of medical staff's emergency capacity during the pandemic and to provide intellectual support to further enhance medical staff's ability to ensure the smooth operation of medical rescue.

Methods: This study conducted a cross-sectional survey of four hospitals designated to treat patients with COVID-19 in China. Based on the emergency capacity system of medical staff for infectious diseases, an improved Emergency Preparedness Information Questionnaire was used to evaluate the emergency capacity of medical staff. Linear regression and one-way analysis of variance were used to test the differences in the emergency capacity of medical staff. Spearman correlation analysis was used to study the correlation between the self-efficacy and emergency capacity of medical staff.

Results: The overall emergency capacity of the surveyed medical staff was at a medium level. There was a correlation between emergency capacity and age, working years, position, educational background and the area where medical staff worked. Emergency capacity was not related to the hospital grade. Emergency capacity was significantly related to whether medical staff had participated in frontline pandemic prevention work. There was also a positive correlation between emergency capacity and the self-efficacy of medical staff.

Conclusions: The results highlight the importance of the training mechanism for emergency personnel. The emergency input for public health emergencies should be increased to improve the emergency capacity of medical staff. In addition, it is necessary to pay attention to the mental health of medical staff.

\section{Background}

In December 2019, the coronavirus disease 2019 (COVID-19) outbreak caused by severe acute respiratory syndrome coronavirus 2 (SARS-CoV-2) occurred in Wuhan, China [1, 2]. With the aggressive spread of SARS-CoV-2, the death toll has been rising worldwide. As of December 27, 2020, COVID-19 had swept across 216 countries and territories, with over 79.2 million cases and over 1.7 million deaths reported. There are serious political, economic and social consequences of COVID-19 for many countries and regions around the world [3].

Swift action to control further spread of the virus and to improve the response capabilities of countries to the severe pandemic is urgent. To minimize the mortality risk of COVID-19, governments and the medical community are taking steps to prevent transmission, ranging from common sense recommendations to radical quarantine measures [4]. In response to public health emergencies, the World Health Organization (WHO) has developed a medical rescue evaluation system for the health system [5]. The Federal Emergency Management Agency (FEMA) and the National Emergency Management Association (NEMA) have jointly proposed the Rescue Self-Assessment Tool [6]. The United States Centers for Disease Control and Prevention (CDC) has presided over the development of a reference manual for state and local public health emergencies [7], and the Indiana State Department of Health has compiled an evaluation tool for long-term care facilities [8]. However, in general, most research focuses on the health system level, the state government level or the medical organization level, but less research focuses on the individual level. Although studies of hospital emergency rescue include some indicators of medical staff for emergency rescue, these indicators are the overall requirements for medical staff from the perspective of hospitals and do not analyse a specific dimension. 
Medical staff, however, are the main force involved in handling epidemics of major infectious diseases. Many medical staff provide technical and intellectual support for emergency medical rescue in every public health emergency. Firstline medical staff and scientists in China have played a crucial role in fighting the outbreak of COVID-19 [9]. Although the pandemic has caused a state of panic, the speed of China's response is reassuring. Chinese scientists, public health professionals and medical staff are striving to pursue pathogens, formulate major measures to reduce the impact of the epidemic, and transparently share the treatment plan and results of epidemic treatment with the global health community in an impressive effort [10]. COVID-19 places unprecedented pressure on societies and health-care systems around the world. In response to this ongoing public health emergency, preparedness and reducing the risk of the global spread of COVID-19 are key concerns [11]. The emergency capacity of medical staff is an essential factor in reducing the case fatality rate and controlling further spread of the pandemic [12]. Therefore, it is necessary to understand the current status of the core emergency capacity of medical staff to provide a reference basis to improve emergency levels and corresponding measures to address the development of the pandemic.

The emergency capacity referred to in this study is the basic ability required for medical staff involved in the emergency rescue of infectious disease emergencies, including relevant knowledge, skills and attitudes. The evaluation index system is usually used to evaluate the emergency capacity of medical staff [13]. To understand the status of medical staff's emergency response capacity in this pandemic, we examined medical staff's infectious disease emergency response capacity system and adopted the improved Emergency Preparedness Information Questionnaire (EPIQ), which was distributed online to hospitals in China.

During the pandemic, rapid and robust research is important to help guide clinical practices and public health policies. The purposes of this study are to analyse the differences in the prevention, preparation and coping capabilities of medical staff with different demographic characteristics; to discuss the correlation between medical staff's prevention, preparation, coping, and self-efficacy; and to investigate the factors that motivate and hinder medical staff from participating in emergency rescue. Understanding the current status of the core emergency capacity of medical staff in China can provide timely information to guide intervention policies, rapidly control the development of the COVID-19 outbreak and reduce the mortality of patients with pneumonia. This information is crucial to inform intervention policies in real-time. The results provide an opportunity to review the emergency capacity of other countries and apply key recommendations from other major public health emergencies to better protect the world from future health emergencies. This study can also prompt the health department to pay attention to frontline doctors and provide adequate protective equipment to reduce their risk of infection. Only in this way can the pandemic be controlled, and patients can continue to seek treatment for other health problems in the hospital.

\section{Methods}

\section{Participants and Data Collection}

We adopted a cross-sectional survey design and an anonymous online questionnaire to assess the emergency capacity of medical staff during the COVID-19 pandemic. A stratified sampling method was used to select hospitals in each province in northern, central and southern China that were designated to treat patients with SARS-CoV-2 pneumonia. The online survey questionnaire was first sent to the managers of the selected hospitals, and they were encouraged to forward the questionnaire to the medical staff of each department of the hospitals to complete and submit.

Four factors should be considered when determining the sample size: the degree of overall variation, the size of the allowable error, the size of the probability guarantee (1-a), and the difference in sampling methods. For example, when 
the overall variance is large, the sample size should also be large. We adopted the formula method to estimate the sample size. The formula method includes the mean method and the ratio method. We chose the ratio equation (1) to estimate the sample size:

$$
n=\frac{Z^{2}(p q)}{e^{2}}
$$

where $n$ represents the sample size and $z$ is the standard error associated with the selected confidence interval. $p$ is the estimated variance of the population, and $q=1-p$. e denotes the acceptable error. In this study, we chose $p=95 \%$, and $e=5 \%$, and the sample size was calculated as follows:

$$
n=\frac{1.96^{2} \times 0.95 \times 0.2}{0.05 \times 0.05} \approx 290
$$

As the Chinese government advocated going out less and not gathering during the COVID-19 pandemic, the use of online questionnaires could obtain large sample data without time and geographical restrictions. Respondents completed the questionnaire in Chinese on an online survey platform ("SurveyStar", Changsha Ranxing Information Technology Co., LTD, Hunan, China). Data collection took place after the number of patients with SARS-CoV-2 pneumonia in China began to decrease gradually and continued for three days (April 5 - 8, 2020). The link to the questionnaire was forwarded to WeChat groups of medical staff by hospital administrators after the questionnaire was edited on the website.

\section{Design of the Survey}

The EPIQ is a widely used emergency capacity assessment tool with good reliability and validity [14]. The scale can be used to develop an evaluation tool that comprehensively evaluates the ability to cope with infectious disease emergencies and the training needs of medical staff. Scholars revised and tested the questionnaire on the basis of the EPIQ when COVID-19 in China was in its worst phase. The results show that the revised EPIQ can be used to investigate the preparedness of medical staff for COVID-19 with good reliability and validity. Based on the questionnaire of Core Emergency Response Capability Indicators of Medical Staff Infectious Disease Emergencies compiled by the Chinese scholar Ting Kan and others [15] and in conjunction with other issues related to the COVID19, we limited the scope of infectious diseases to COVID-19. On the basis of the original questionnaire, we deleted "understand the response to bioterrorism attacks" in Item 36 and modified "understand the emergency response to infectious diseases after natural disasters" in Item 37 to "understand the COVID-19 emergency response". The final scale was composed of three dimensions, i.e., prevention ability, preparation ability and coping ability, with a total of 37 items. The response scale for each question was a seven-point Likert scale, where $1=$ very unfamiliar and $7=$ very familiar. The higher the score, the stronger the core emergency response capability. Targeted training in response to the lack of emergency capacity can enhance the self-efficacy of medical staff in response to public health emergencies, thereby enhancing their willingness to participate in rescue [16]. Therefore, at the end of the questionnaire, content on medical staff's self-efficacy was added. The structured questionnaire included the following aspects.

Sociodemographic data were collected on gender, age, working years, position, educational attainment, region and hospital grade. Respondents were asked to answer whether they had participated in the first-line anti-pandemic 
activities.

Prevention capabilities were composed of 1 secondary indicator and 3 items. Respondents were asked to identify the extent to which they grasped the infection spectrum of COVID-19, including the concepts and significance of the incubation period, infectious period, recessive infection, and dominant infection. They were also asked whether they knew about the spread of COVID-19 and principles for mastering the prevention and control of COVID-19.

Preparation capabilities were composed of 4 secondary indicators and 6 items. Variables about preparation ability included familiarity with the responsibilities of medical staff in the National Emergency Response Plan for Public Health Emergencies and the National Emergency Response Plan for Medical Emergencies; and the degree of understanding of the Emergency Regulations on Public Health Incidents and the Law of the People's Republic of China on the Prevention and Control of Infectious Diseases. Respondents were asked whether they regularly participated in emergency exercises for infectious disease emergencies and whether they regularly participated in training for common and emerging infectious diseases.

Coping capabilities were composed of 6 secondary indicators and 28 items, including content on monitoring, reporting, medical response, public health response, risk communication, and the response to COVID-19 in specific situations. Respondents were asked whether they understood the meaning of symptom monitoring and whether they remembered the definition of syndrome and the legal reporting period for infectious diseases. They were also asked whether they had memorized the scope and process of the COVID-19 related information report, whether basic knowledge of medical response to the COVID-19 was mastered, and whether the collection of specimens was implemented for patients. In addition, variables included the degree of understanding of the precautions for specimen storage and transportation and whether key information could be obtained from the selected information sources. Respondents were also asked about their degree of mastery of safety protection, infection control, and isolation measures; whether they participated in the health education programme for infectious disease control; and whether they had the ability to communicate with patients on psychological counselling and other risks. Finally, the respondents were asked about some precautions for specific circumstances such as a global pandemic and participation in international rescue.

The self-efficacy of medical staff was measured by using the General Self-Efficacy Scale (GSES) [17-19]. The Chinese version of the GSES has been well-validated in China for determining individuals' perception or belief that they can adopt adaptive behaviour in the face of challenges in the environment [20]. The GSES in this research had a total of 10 items involving medical staff's self-confidence when they encounter setbacks or difficulties while fighting COVID-19. The response scale for each question was a five-point Likert scale. For each item, respondents answered "completely incorrect", "somewhat correct", "uncertain", "mostly correct", or "completely correct" according to their actual situation. During scoring, "completely incorrect" scored 1 point, "somewhat correct" scored 2 points, "uncertain" scored 3 points, "mostly correct" scored 4 points, and "completely correct" scored 5 points.

\section{Data Analysis}

Descriptive statistics were calculated to understand sociodemographic characteristics, prevention ability variables, preparation ability variables, coping ability variables, and self-efficacy variables to assess the current status of medical staff's ability to prevent, prepare and rescue COVID-19 cases. Linear regression, one-way analysis of variance and the Kruskal-Wallis $\mathrm{H}$ test were used to study differences in demographic characteristics in the capacity to prevent, prepare for, and cope with COVID-19. Spearman correlation analysis was applied to study the correlation between selfefficacy and medical staff's ability to prevent, prepare and rescue. All tests were two-tailed and the significance level 
was $p<0.05$. STATA Statistics/Data Analysis 15.1 was used for statistical analysis (StataCorp LLC, Texas, United States).

\section{Results}

\section{The Cure of Patients with SARS-CoV-2 in China from February 1 to March 31, 2020}

Figure 1 shows the changes in the existing diagnosed patients, the cumulative number of cured patients, and the cumulative death toll with SARS-CoV-2 in February and March, 2020 in Hubei Province, China. The cumulative number of cured patients increased exponentially over the previous two months. The cumulative death toll also increased, but not as strongly as the former. The number of existing diagnosed patients, however, had a bell-shaped distribution. An inflection point appeared on February 19. The number of patients diagnosed in Hubei Province had increased geometrically daily until February 19, and the total number of confirmed cases gradually decreased until February 20. It is worth noting that the cumulative number of cured patients on February 29 exceeded the number of existing diagnosed patients, and the gap between them was widening in a trumpet shape.

\section{Participants in the Survey}

We received responses from 483 participants; and 126 participants did not complete the questionnaire. Ultimately, we included 357 participants from 4 hospitals, which were all hospitals selected to treat patients with SARS-CoV-2 pneumonia in China (completion rate: 73.91\%). A total of 174 participants submitted the questionnaire on the first day (6 April), and 278 participants submitted the questionnaire on the second day (7 April). Only 31 participants submitted the questionnaire on the third day (8 April).

The emergency capacity of medical staff was measured using the EPIQ scale. For simplicity, all three variables were calculated as the means of their respective items (with negative items reverse-coded). In the overall dimension of prevention ability, the sample mean was $5.98(S D=1.03)$. Of all respondents, $5(1.4 \%)$ were considered weak in prevention (score < 3), 90 (25.2\%) were considered to have a moderate level of prevention (score: $3-5$ ), and 262 $(73.4 \%)$ were considered to have strong prevention ability (score $>5$ ). In the overall dimension of preparation ability, the sample mean was $5.11(S D=1.22)$. Of all respondents, $33(9.2 \%)$ were considered weak in preparation (score < 3 ), 97 (27.2\%) were considered to have a moderate level of preparation (score: 3-5), and 206 (57.7\%) were considered to have strong preparation ability (score $>5$ ). In the overall dimension of coping ability, the sample mean was $5.54(S D=$ 1.07). Of all respondents, 11 (3.1\%) were considered weak in coping (score < 3), 100 (28.0\%) were considered to have moderate coping ability (score: $3-5)$, and 246 (68.9\%) were considered to have strong coping ability (score > 5).

The self-efficacy level of the medical staff was measured using the GSES scale, and the overall mean of the sample was $3.86(S D=0.65)$. Specifically, $6(1.7 \%)$ were not confident enough to complete the tasks they were assigned (score: 1-2), 85 (23.8\%) were considered to have general confidence and could barely complete the tasks they were assigned (score: 3 ), and 266 (74.5\%) were considered relatively confident and could better complete the tasks they were assigned (score: $4-5)$.

\section{Sociodemographic Variables and Emergency Capacity of Medical Staff}


Sociodemographic characteristics are presented in Table 1 . The majority of participants were women (85.9\%) aged 21 to 30 years (52.7\%); they had worked less than 11 years (63.3\%), had a bachelor's degree $(59.9 \%)$, were clinical nurses (60.5\%), and worked in Shaanxi Province (55.2\%) and secondary hospitals (89.9\%). Nearly half of the respondents were frontline medical staff during the COVID-19 pandemic (43.7\%). Male gender was significantly associated with higher scores on the EPIQ preparation ability subscale ( $\mathrm{B}=0.32,95 \%$ confidence interval $(95 \% \mathrm{Cl}): 0.00$ to 0.64$)$. Age 21 to 30 years was significantly associated with a lower EPIQ preparation ability subscale $(B=-0.54,95 \% \mathrm{Cl}$ : -1.13 to 0.06). Low working-years were significantly associated with lower EPIQ preparation ability subscale scores $(B=-0.55$, $95 \% \mathrm{Cl}:-1.13$ to 0.03$)$ and EPIQ coping ability subscale scores $(\mathrm{B}=-0.44,95 \% \mathrm{Cl}$ : -0.95 to 0.07$)$. Participants with 11 to 20 working years were significantly associated with lower EPIQ coping ability subscale scores $(B=-0.51,95 \%$ Cl: -1.06 to 0.05$)$ compared to those who had worked from 31 to 40 years. Participants with a high school degree were significantly associated with lower EPIQ prevention ability subscale scores (B $=-2.90,95 \% \mathrm{Cl}$ : -5.16 to -0.61$)$ than those with a PhD. Clinical nurse status was significantly associated with a lower EPIQ preparation ability subscale $(\mathrm{B}=-0.45,95 \% \mathrm{Cl}:-0.82$ to -0.09$)$. Clinicist status was significantly associated with a lower EPIQ preparation ability subscale ( $\mathrm{B}=-1.62,95 \% \mathrm{Cl}$ : -2.84 to -0.39$)$ and a lower EPIQ coping ability subscale ( $\mathrm{B}=-1.46,95 \% \mathrm{Cl}$ : -2.53 to -0.38$)$. The status of frontline medical staff was significantly associated

with a higher EPIQ prevention ability subscale $(\mathrm{B}=0.33,95 \% \mathrm{Cl}: 0.12$ to 0.55$)$, higher EPIQ preparation ability subscale ( $\mathrm{B}=0.39,95 \% \mathrm{Cl}$ : 0.14 to 0.64$)$, and higher EPIQ coping ability subscale ( $\mathrm{B}=0.43,95 \% \mathrm{Cl}: 0.21$ to 0.65$)$. Working in Shaanxi Province was significantly associated with a higher EPIQ prevention ability subscale $(\mathrm{B}=0.34,95 \% \mathrm{Cl}$ : 0.08 to 0.60$)$. Working in Hubei Province was significantly associated with a higher EPIQ prevention ability subscale (B = $0.53,95 \% \mathrm{Cl}: 0.21$ to 0.85 ), higher EPIQ preparation ability subscale ( $\mathrm{B}=0.36,95 \% \mathrm{Cl}:-0.02$ to 0.73 ), and higher EPIQ coping ability subscale $(B=0.32,95 \% \mathrm{Cl}$ : -0.01 to 0.65$)$. Other sociodemographic variables, such as hospital grade, were not associated with EPIQ subscale scores.

\section{Participation and Emergency Capacity}

Table 2 shows the difference between the scores of frontline medical staff and non-frontline medical staff in the three dimensions of emergency capacity. Overall, frontline medical staff scored significantly higher in every dimension than non-frontline medical staff $(p<0.01)$. For prevention ability, the total score of frontline medical staff $(M=18.51, S D=$ 2.61) was 1 point higher than that of non-frontline medical staff $(M=17.51, S D=3.35)$. For preparation ability, the total score of frontline medical staff $(M=31.96, S D=6.50)$ was 2 points higher than that of non-frontline medical staff $(M=29.62, S D=7.79)$. For coping ability, the total score of frontline medical staff $(M=161.96, S D=24.30)$ was 11 points higher than that of non-frontline medical staff $(M=150.01, S D=32.60)$.

\section{Region and Emergency Capacity}

Regarding the regions where respondents worked, Table 3 shows a significant difference in the emergency capacity of medical staff between regions. There were differences between the three regions in terms of prevention ability and preparation ability $(p<0.05)$. In general, the emergency capacity of medical staff in Hubei was higher than that of the other two regions. For prevention ability, the total score of medical staff in Hubei $(M=18.63, S D=2.30)$ was 0.5 points higher than that of medical staff in Shaanxi $(M=18.06, S D=3.09)$ and 1.5 points higher than that of medical staff in Yunnan $(M=17.04, S D=3.53)$. For preparation ability, the total score of medical staff in Hubei $(M=32.67, S D=5.58)$ was 2.5 points higher than that of medical staff in Shaanxi $(M=29.89, S D=8.06)$ and 2 points higher than that of medical staff in Yunnan $(M=30.52, S D=6.67)$. For coping ability, the total score of medical staff in Hubei $(M=$ 
$161.23, S D=24.39)$ was 7 points higher than that of medical staff in Shaanxi $(M=154.10, S D=30.89)$ and 9 points higher than that of medical staff in Yunnan $(M=152.24, S D=31.42)$.

\section{Self-efficacy and Emergency Capacity}

Table 4 shows the relationship between the emergency capacity and self-efficacy of medical staff. There was a significant positive correlation between prevention ability and preparation ability $(r=0.598, p<0.001)$, a significant positive correlation between prevention ability and coping ability $(r=0.627, p<0.001)$, and a significant positive correlation between preparation ability and coping ability $(r=0.761, p<0.001)$. There was a significant positive correlation between self-efficacy and prevention ability $(r=0.202, p<0.001)$, a significant positive correlation between self-efficacy and preparation ability $(r=0.358, p<0.001)$, and a significant positive correlation between self-efficacy and coping ability $(r=0.376, p<0.001)$. Figure 2 shows the relationship between medical staff's self-efficacy and various dimensions of emergency capacity. There was a strong correlation between all dimensions of emergency capacity $(r>0.5, p<0.001)$. Medical staff's self-efficacy was positively correlated with all dimensions of emergency capacity, but not strongly $(r<0.5, p<0.001)$.

\section{Discussion}

To ease the further spread of COVID-19, and for the safety of the people, the Chinese government used all its power to contain the disease. Both in the supply of medical equipment and medical staff and the stable development of other industries, China has made all efforts to stabilize the pandemic [21]. Wuhan City, Hubei Province, was the centre of the COVID-19 in China. However, due to the strong leadership of the Communist Party of China, a series of major decisions, such as the concentration of outstanding national medical staff to support Hubei, were issued immediately. For the sake of people's security and national stability, the Chinese government urgently deployed 68 medical teams, including more than 8000 medical staff from all over China; these were the most acclaimed and proficient medical staff in their respective provinces and cities. They were on a mission to Hubei Province, the hardesthit province, to fight side by side in hospitals with people from Wuhan and other parts of the country [22, 23]. Healthcare professionals worked day and night since January 20, unwilling to give up any patient; as a result, the number of newly cured patients and the cure rate were gradually rising in February and March 2020, and the increase in the cumulative number of cured patients was much greater than the increase in the number of deaths. This demonstrates that medical staff are indispensable in pandemic prevention and control.

We analysed the correlation of medical staff's emergency capacity scores with demographic variables such as gender, age, working years, education, occupation, and hospital grade. Our estimates suggest that the younger age groups had a lower emergency capacity than the older, more senior and highly educated medical staff. In past outbreaks, scholars have performed many investigations and studies. It was found that gender had some influence on ability in health interventions. During the Ebola outbreak in Africa from 2014 to 2016, scholars found that women were more susceptible to the disease due to their primary role as caregivers in the family and frontline medical workers [24]. To promote gender equality and meet public health standards, scholars advocate that gender should be included in disaster preparedness and response to improve health effectiveness, because women have less voice and decisionmaking power than men at the time of an outbreak [25]. Our results in this study, further support this view as males were significantly better than females in terms of pandemic preparedness.

It is clear from the data from three regions of China that the emergency capacity of frontline medical staff was significantly higher than that of non-frontline medical staff. Our results also suggest that the emergency capacity of 
medical staff in Hubei was higher than that of the other two regions. It is unclear why emergency capacity differed significantly between regions, but many medical teams supporting Hubei had received pre-job training from local experts in Hubei before going to the front line of the fight against COVID-19 [26, 27]. Pre-job training aims to improve the prevention and control level of medical staff and help medical staff strengthen their awareness of protection, implement personal protection measures, and protect their health during the anti-pandemic period. The experts introduced the discovery and report of SARS-CoV-2 cases, epidemiological investigation, medical treatment, hospital infection prevention and control, close contact management, personal protection and other content for the medical teams supporting Hubei in combination with the characteristics of the local outbreak [28]. This may be the reason why medical staff who had participated in first-line pandemic prevention had a stronger emergency capacity than medical staff who had not.

In this study, we also analysed the relationship between medical staff's self-efficacy and emergency capacity. Existing studies have shown that training experience can affect the willingness of medical staff to participate in rescue during public health emergencies $[29,30]$. Targeted training can enhance the self-efficacy of medical staff in responding to public health emergencies, thereby enhancing their willingness to participate in rescue [16]. Training experience is also a positive predictor of the coping ability of medical staff [31]. Our findings suggest that there is a significant positive correlation between medical staff's self-efficacy and emergency capacity.

Training medical staff in responding to public health emergencies and specific COVID-19 programmes is critical [3234]. Medical staff have played a crucial role in responding to disease outbreaks such as SARS, Ebola virus, cholera and measles. The main lesson of these public health emergencies is to ensure that these skills are further developed [35]. Given the low capacity of many countries to effectively prevent and respond to health emergencies, our data reinforce this notion.

Personnel training is essential to ensure preparedness and success in dealing with any pandemic. Regardless of how COVID-19 evolves, medical staff must be prepared and trained to apply early and optimal interventions. We call on governments and global health institutions to consider the role of training programmes in improving emergency abilities. With the huge efforts from medical staff to treat patients, we hope that downward turning points for both new cases of COVID-19 and resulting fatal events are imminent. Practical measures can be taken. First, hospital administrators, governments, and policymakers must work with medical staff. They must protect medical staff from cross-infection, physical exhaustion, and mental health issues, ensure access to drugs and protective equipment, discuss advance care plans, and provide better training and preparation across the health workforce. Second, medical staff are under enormous psychological pressure due to overwork, shortage of medical resources, poor doctor-patient relationships, or other detrimental experiences [36]. Medical staff should be provided with adequate psychological support, to understand their own psychological characteristics, learn to diagnose their own psychological problems, reasonably ease their emotions, and improve their sense of self-efficacy. Third, training programmes should be led by expert members of the local team with support from other professionals (e.g., infection control) and formulated into guidelines for clinical management; such guidelines should be provided to all members of the local teams. Fourth, online platforms with medical advice should be provided to share information on how to reduce the risk of transmission between patients in the medical environment with the aim of ultimately reducing the pressure on medical staff. Fifth, the proper use of personal protective equipment and proper handling of infected bodily secretions and laboratory specimens are basic skills for medical staff and all other institutional staff to manage any pandemic. After sufficient training, all equipment related to emergency rescue must be drilled as a team in a high-fidelity simulation environment. 
Our study has several limitations. First, only a few male medical staff were involved in this study. Due to the suddenness and particularity of the COVID-19, hospital in China lacked nursing assistant and support staff, and nurses have undertaken a lot of heavy work. On the front line of China's fight against the COVID-19, the vast majority of medical staff are nurses. However, women's prescribed care roles in society usually place them in the best position to identify trends at the local level that may herald disease outbreaks and thus improve global health security. Although the WHO executive board recognizes the need to include women in decision-making for outbreak preparedness and response [37], there is inadequate representation of women in national and global COVID-19 policy areas, such as in the White House Coronavirus Task Force [38]. Therefore, we should consider gender balance when distributing the questionnaire in order to further analyse gender differences in response to the pandemic. Second, we paid more attention to the performance of the medical staff in the treatment capacity, but neglected the mental ability of medical staff. Medical staff in high-risk units are especially vulnerable to mental health problems, including anxiety and depression, during outbreaks such as COVID-19, because of the demanding workload and constant fear of crossinfection [39]. Health-care workers who worked in SARS ICUs continued to suffer from posttraumatic stress disorder years later [40]. We should consider the effects of medical staff's psychological status on self-efficacy during the pandemic. Third, higher-quality clinical services for patients with infectious diseases will yield a significant reduction in mortality during future outbreaks [41]. The management of patients with infectious diseases is a significant issue that can affect the outcomes of prehospital mortality and morbidity [42]. However, we paid more attention to preparation and clinical service processes and lacked an evaluation of the treatment effect of the respondents on patients. Therefore, if the clinical results of patients can be evaluated in future research, the effectiveness of preparedness for public health emergencies could be better evaluated. Finally, the overall generalizability of these results outside of China may be some limited given the differences in healthcare workers in other settings. Despite these limitations, this study provides valuable information on the emergency capacity status of medical staff in three regions of China. Our results could be used as a reference for other public health events. Most importantly, our findings directly indicate that a series of training sessions can be used to improve the self-efficacy and emergency capacity of medical staff. This finding has clinical and policy implications.

\section{Conclusions}

Our study provides a detailed overview of the emergency response capabilities of medical staff in the three regions of north, central, and south China. Our findings suggest that the emergency capacity of medical staff participating in first-line pandemic prevention was stronger than that of medical staff who did not participate; the emergency capacity of medical staff in Hubei was better than that in other regions; and there was a high positive correlation between the self-efficacy and emergency response capabilities of medical staff. These results indicate that it is necessary to provide targeted training to improve the emergency capacity of medical staff to curb the rapid spread of the pandemic. The pandemic continues to be severe, with frontline health workers at risk of infection and undergoing both physical and psychological tests. In addition to personal protection for medical staff, timely psychological support should be provided to improve their sense of self-efficacy. Only in this way will they be more capable of facing the challenge of COVID-19.

\section{Abbreviations}

COVID-19: Coronavirus disease 2019; SARS-CoV-2: severe acute respiratory syndrome coronavirus 2; WHO: World Health Organization; FEMA: Federal Emergency Management Agency; NEMA: National Emergency Management Association; CDC: Centers for Disease Control and Prevention; EPIQ: Emergency Preparedness Information Questionnaire; GSES: General Self-Efficacy Scale; R²: R-Squared; AR²: Adjusted R-Squared; CI: Confidence Interval

Page $10 / 18$ 


\section{Declarations}

\section{Ethics approval and consent to participate}

This study was approved by the Ethics Committee of School of Medicine of Xi'an Jiaotong University (China), and the approval number was 2020-1258. Verbal informed consent was received from the participants to use the information anonymously for the purpose of this study.

\section{Consent for publication}

Not applicable.

\section{Availability of data and materials}

The datasets used and/or analysed during the current study are available from the corresponding author on reasonable request.

\section{Competing interests}

The authors declare that they have no competing interests.

\section{Funding}

There was no external funding received for this research.

\section{Authors' contributions}

HSX contributed significantly to the study conceptualization and writing supervision. LQ contributed significantly to data collection. CCF and ZGF contributed significantly to the analysis of data and the writing of the first draft. CHL and $Z Y X$ contributed significantly to the revisions of the manuscript. All authors have read and approved the manuscript in its current form.

\section{Acknowledgments}

We would like to express our appreciation to the Baoji Hi-tech People's Hospital, Hanzhong Railway Central Hospital, XiangYang Hospital of Traditional Chinese Medicine and MiLe Hospital of TCM, particularly to Director of Hospital Mr. $\mathrm{Ma}$ and Mr. Wang for their assistance and sincere thanks to all medical staff who participated in this survey.

\section{References}

1. Huang C, Wang Y, Li X, Ren L, Zhao J, Hu Y, Zhang L, Fan G, Xu J, Gu X et al. Clinical features of patients infected with 2019 novel coronavirus in Wuhan, China. The Lancet. 2020; 395(10223):497-506. 
2. Holshue ML, DeBolt C, Lindquist S, Lofy KH, Wiesman J, Bruce H, Spitters C, Ericson K, Wilkerson S, Tural A et al. First Case of 2019 Novel Coronavirus in the United States. N Engl J Med. 2020; 382(10):929-936.

3. WHO. Weekly Epidemiological and Operational updates December 2020. 2020. Available from: https://www.who.int/emergencies/diseases/novel-coronavirus-2019/situation-reports/. Accessed on December 292020.

4. Xiao Y, Torok ME. Taking the right measures to control COVID-19. The Lancet Infectious Diseases. 2020.

5. World Health Organization. Toolkit for assessing health-system capacity for crisis management. 2012. Available from: http://www.euro.who.int/_data/assets/pdf_file/0008/157886/e96187.pdf?ua=1. Accessed on August 22 2012.

6. Doll R. FEMA's Compliance Assessment Tool.(FYI)(Federal Emergency Management Agency)(National Incident Management Compliance Assessment Support Tool)(Brief Article). Risk Management. 2012; 59(7):S544-S545.

7. The Centers for Disease Control and Prevention. Public Health Emergencies Reference Manual. 2002. Available from: https://www.in.gov/isdh/files/Public_Health_Emergencies_Reference_Manual.pdf. Accessed on July 30 2002.

8. Indiana State Department of Health. The Indiana State Department of Health has created a COVID-19 toolkit for Long-Term Care Facility Staff. 2020. Available from: https://www.coronavirus.in.gov/files/IN_COVID19\%20IP\%20Toolkit\%20ISDH_5.16.2020.pdf. Accessed on April 72020.

9. Wang F-S, Zhang C. What to do next to control the 2019-nCoV epidemic? The Lancet. 2020; 395(10222):391-393.

10. Calisher C, Carroll D, Colwell R, Corley RB, Daszak P, Drosten C, Enjuanes L, Farrar J, Field H, Golding J et al. Statement in support of the scientists, public health professionals, and medical professionals of China combatting COVID-19. The Lancet. 2020; 395(10226):e42-e43.

11. McCloskey B, Zumla A, Ippolito G, Blumberg L, Arbon P, Cicero A, Endericks T, Lim PL, Borodina M. Mass gathering events and reducing further global spread of COVID-19: a political and public health dilemma. The Lancet. 2020; 395(10230):1096-1099.

12. Onder G, Rezza G, Brusaferro S. Case-Fatality Rate and Characteristics of Patients Dying in Relation to COVID-19 in Italy. JAMA. 2020.

13. Armacost RL, Pet-Armacost JJA. Risk-based management of waterway safety. International Journal of Emergency Management 2002(2):96-109.

14. Georgino MM, Kress T, Alexander S, Beach M. Emergency Preparedness Education for Nurses: Core Competency Familiarity Measured Utilizing an Adapted Emergency Preparedness Information Questionnaire. J Trauma Nurs. 2015; 22(5):240-248; quiz E241-242.

15. Kan T. Development and Evaluation of Training Program for Infectious Disease Emergencies Response Competence of Healthcare Workers. Doctor. The Second Military Medical University. 2018. Article in Chinese.

16. Barnett DJ, Thompson CB, Semon NL, Errett NA, Harrison KL, Anderson MK, Ferrell JL, Freiheit JM, Hudson R, McKee $\mathrm{M}$ et al. EPPM and willingness to respond: the role of risk and efficacy communication in strengthening public health emergency response systems. Health Commun. 2014; 29(6):598-609.

17. Schwarzer R, Born A. Optimistic self-beliefs: Assessment of general perceived self-efficacy in thirteen cultures. World Psychology. 1997; 3:177-190.

18. Schwarzer R, Born A, Iwawaki S, Lee Y-M, Saito E, Yue X. The assessment of optimistic self-beliefs-Comparison of the Chinese, Indonesian, Japanese and Korean Versions of the general self-efficacy scale. Psychologia : An International Journal of Psychology in the Orient. 1997; 40(1):1-13. 
19. Schwarzer R, Mueller J, Greenglass E. Assessment of perceived general self-efficacy on the Internet: Data collection in cyberspace. Anxiety, Stress \& Coping: An International Journal. 1999; 12(2):145-161.

20. W C, H Z, L Y. General SelfEfficacy Scale (GSES) Reliability Construct Validity and Prediction Validity. Chinese Journal of Applied Psychology. 2001(01):37-40.

21. World Health Organization. Report of the WHO-China Joint Mission on Coronavirus Disease 2019 (COVID-19). 2020. Available from: https://www.who.int/publications-detail/report-of-the-who-china-joint-mission-oncoronavirus-disease-2019-(covid-19). Accessed on February 282020.

22. XINHUA NET. 68 medical teams sent to Hubei to aid coronavirus control. 2020. Available from: http://www.xinhuanet.com/english/2020-02/03/c_138752003.htm. Accessed on February 42020.

23. National Health Commission of the People's Republic of China. The guideline of psychological crisis intervention for 2019-nCoV pneumonia. 2020. Available from:

http://www.nhc.gov.cn/jkj/s3577/202001/6adc08b966594253b2b791be5c3b9467.shtml. Accessed on January 272020.

24. Health News. Angels in white put on the white coat and set off to support Hubei. 2020. Available from: http://szb.jkb.com.cn/jkbpaper/html/2020-03/12/content_271749.htm. Accessed on March 122020.

25. Harman S. Ebola, gender and conspicuously invisible women in global health governance. Third World Quarterly. 2016; 37(3):524-541.

26. Tianshui Health Commission. The first batch of medical teams from Gansu to Hubei have completed pre-service training to against the epidemic. 2020. Available from: http://www.tianshui.gov.cn/art/2020/1/31/art_352_238933.html. Accessed on January 312020.

27. Nanchang News. The medical team to support Hubei completed the training and officially entered the ward of Wuhan Fifth Hospital. 2020. Available from:

http://news.ncnews.com.cn/ylxw/202002/t20200211_1537040.html. Accessed on February 112020.

28. Sohu News. Karamay City Medical Team supporting Hubei has Completed Pre-job Training. 2020. Available from: https://www.sohu.com/a/371334129_697417. Accessed on February 72020.

29. Bell MA, Dake JA, Price JH, Jordan TR, Rega P. A national survey of emergency nurses and avian influenza threat. J Emerg Nurs. 2014; 40(3):212-217; quiz 294-215.

30. Barnett DJ, Thompson CB, Errett NA, Semon NL, Anderson MK, Ferrell JL, Freiheit JM, Hudson R, Koch MM, McKee $\mathrm{M}$ et al. Determinants of emergency response willingness in the local public health workforce by jurisdictional and scenario patterns: a cross-sectional survey. BMC Public Health. 2012; 12:164.

31. Yu C, Huang Y, Wang X, Yang H, Wang J, Zhou Z. Investigation and analysis of current situation of health emergency ability of community medical staff in Guangdong province. Chinese General Practice. 2014; 17(1):9193.

32. Qiu H, Tong Z, Ma P, Hu M, Peng Z, Wu W, Du B, China Critical Care Clinical Trials G. Intensive care during the coronavirus epidemic. Intensive Care Med. 2020; 46(4):576-578.

33. Gomersall CD, Tai DY, Loo S, Derrick JL, Goh MS, Buckley TA, Chua C, Ho KM, Raghavan GP, Ho OM et al. Expanding ICU facilities in an epidemic: recommendations based on experience from the SARS epidemic in Hong Kong and Singapore. Intensive Care Med. 2006; 32(7):1004-1013.

34. Einav S, Hick JL, Hanfling D, Erstad BL, Toner ES, Branson RD, Kanter RK, Kissoon N, Dichter JR, Devereaux AV et al. Surge capacity logistics: care of the critically ill and injured during pandemics and disasters: CHEST consensus statement. Chest. 2014; 146(4 Suppl):e17S-43S. 
35. Lim SS, Updike RL, Kaldjian AS, Barber RM, Cowling K, York H, Friedman J, Xu R, Whisnant JL, Taylor HJ et al. Measuring human capital: a systematic analysis of 195 countries and territories, 1990-2016. The Lancet. 2018; 392(10154):1217-1234.

36. Wang J, Qi H, Bao L, Li F, Shi Y. A contingency plan for the management of the 2019 novel coronavirus outbreak in neonatal intensive care units. The Lancet Child \& Adolescent Health. 2020; 4(4):258-259.

37. World Health Organization. Strengthening Preparedness for Health Emergencies; Implementation of International Health Regulations (IHR, 2005). 2020. Available from: https://apps.who.int/gb/ebwha/pdf_files/EB146/B146_CONF17-en.pdf. Accessed on February 82020.

38. The Economic Times. Indian-American Seema Verma appointed as key member of US COVID-19 task force 2020. Available from: https://economictimes.indiatimes.com/nri/nris-in-news/indian-american-seema-vermaappointed-as-key-member-of-us-covid-19-task-force/articleshow/74454795.cms. Accessed on March 32020.

39. Xiang Y-T, Yang Y, Li W, Zhang L, Zhang Q, Cheung T, Ng CH. Timely mental health care for the 2019 novel coronavirus outbreak is urgently needed. The Lancet Psychiatry. 2020; 7(3):228-229.

40. Ping W. The psychological impact of the SARS epidemic on hospital employees in China: exposure, risk perception, and altruistic acceptance of risk. Canadian journal of psychiatry Revue canadienne de psychiatrie. 2009; 5(54).

41. Agrawal S, Golebiowska J, Bartoszewicz B, Makuch S, Mazur G. Clinical preventive services to reduce pandemic deaths. Prev Med Rep. 2020; 20:101249.

42. Sadeghi-Bazargani H, Amir-Behghadami M, Gholizadeh M, Janati A, Rahmani F. Preparedness of non-hospital health centers to manage patients with life-threatening emergency conditions: findings from a qualitative study. BMC Health Serv Res. 2020; 20(1):1129.

\section{Tables}

Table 1. Association between demographic variables and emergency capacities of medical staff during the fight against COVID-19 


\begin{tabular}{|c|c|c|c|c|c|c|c|c|c|c|}
\hline \multirow[t]{2}{*}{ Variable } & \multirow[t]{2}{*}{$\mathbf{N}(\%)$} & \multicolumn{3}{|c|}{ Prevention ability } & \multicolumn{3}{|c|}{ Preparation ability } & \multicolumn{3}{|c|}{ Coping ability } \\
\hline & & $\begin{array}{c}\text { R- } \\
\text { Squared } \\
\left(\mathbf{R}^{2}\right)\end{array}$ & $\begin{array}{l}\text { Adjusted } \\
\text { R- } \\
\text { Squared } \\
\left(\mathrm{AR}^{2}\right)\end{array}$ & $\begin{array}{c}\text { Beta }(95 \% \\
\text { Confidence } \\
\text { Interval) or B } \\
(95 \% \mathrm{CI})\end{array}$ & $\mathrm{R}^{2}$ & $\mathrm{AR}^{2}$ & B $(95 \% \mathrm{CI})$ & $\mathrm{R}^{2}$ & $\mathrm{AR}^{2}$ & B (95\% CI) \\
\hline \multicolumn{11}{|l|}{ Gender } \\
\hline Male & $68(19.1)$ & 0.002 & -0.001 & $\begin{array}{l}0.12(-0.15 \\
\text { to } 0.40)\end{array}$ & 0.011 & 0.008 & $\begin{array}{l}0.32 * *(0.00 \\
\text { to } 0.64)\end{array}$ & 0.006 & 0.003 & $\begin{array}{c}0.20(-0.08 \text { to } \\
0.48)\end{array}$ \\
\hline Female & $289(85.9)$ & & & Reference & & & Reference & & & Reference \\
\hline $\begin{array}{l}\text { Age (Years) } \\
\text { (under 21) }\end{array}$ & $4(1.1)$ & & & $\begin{array}{c}0.04(-1.07 \\
\text { to } 1.15)\end{array}$ & & & $\begin{array}{c}0.09(-1.23 \text { to } \\
1.41)\end{array}$ & & & $\begin{array}{c}0.05(-1.12 \text { to } \\
1.21)\end{array}$ \\
\hline$(21-30)$ & $188(52.7)$ & 0.044 & 0.033 & $\begin{array}{c}-0.47(-0.98 \\
\text { to } 0.03)\end{array}$ & 0.034 & 0.023 & $\begin{array}{c}-0.54 *(-1.13 \\
\text { to } 0.06)\end{array}$ & 0.009 & -0.003 & $\begin{array}{c}-0.33(-0.86 \\
\text { to } 0.20)\end{array}$ \\
\hline$(31-40)$ & $91(25.5)$ & & & $\begin{array}{c}-0.30(-0.83 \\
\text { to } 0.22)\end{array}$ & & & $\begin{array}{c}-0.26(-0.88 \\
\text { to } 0.37)\end{array}$ & & & $\begin{array}{c}-0.29(-0.84 \\
\text { to } 0.27)\end{array}$ \\
\hline$(41-50)$ & $57(16.0)$ & & & $\begin{array}{l}0.10(-0.45 \\
\text { to } 0.65)\end{array}$ & & & $\begin{array}{c}0.02(-0.63 \text { to } \\
0.68)\end{array}$ & & & $\begin{array}{c}-0.12(-0.70 \\
\text { to } 0.45)\end{array}$ \\
\hline$(51-60)$ & $17(4.7)$ & & & Reference & & & Reference & & & Reference \\
\hline \multicolumn{11}{|l|}{$\begin{array}{l}\text { Working } \\
\text { years }\end{array}$} \\
\hline (under 11) & $226(63.3)$ & & & $\begin{array}{c}-0.40(-0.89 \\
\text { to } 0.09)\end{array}$ & & & $-0.55 *(-1.13$ & 0016 & 0.007 & $-0.44 *(-0.95$ \\
\hline$(11-20)$ & $64(17.9)$ & 0.039 & 0.031 & $\begin{array}{c}\text { to } 0.09) \\
-0.44(-0.97 \\
\text { to } 0.09)\end{array}$ & 0.025 & 0.017 & $\begin{array}{l}-0.51(-1.14 \\
\text { to } 0.13)\end{array}$ & 0.016 & 0.007 & $\begin{array}{c}-0.51 *(-1.06 \\
\text { to } 0.05)\end{array}$ \\
\hline$(21-30)$ & $49(13.7)$ & & & $\begin{array}{l}0.15(-0.40 \\
\text { to } 0.70)\end{array}$ & & & $\begin{array}{c}-0.07(-0.73 \\
\text { to } 0.59)\end{array}$ & & & $\begin{array}{c}-0.76(-0.76 \\
\text { to } 0.39)\end{array}$ \\
\hline$(31-41)$ & $18(5.1)$ & & & Reference & & & Reference & & & Reference \\
\hline \multicolumn{11}{|l|}{$\begin{array}{l}\text { Educational } \\
\text { attainment }\end{array}$} \\
\hline $\begin{array}{l}\text { Upper } \\
\text { secondary }\end{array}$ & $3(0.8)$ & & & $\begin{array}{c}-2.9 * *(-5.16 \\
\text { to }-0.61)\end{array}$ & & & $\begin{array}{c}-1.61(-4.37 \\
\text { to } 1.15)\end{array}$ & & & $\begin{array}{c}-1.29(-3.69 \\
\text { to } 1.11)\end{array}$ \\
\hline school & & 0.063 & 0.053 & & 0.023 & 0.012 & & 0.027 & 0.016 & \\
\hline $\begin{array}{l}\text { Associate } \\
\text { degree }\end{array}$ & $130(36.5)$ & & & $\begin{array}{c}-1.24(-3.22 \\
\text { to } 0.73)\end{array}$ & & & $\begin{array}{c}-0.20(-2.60 \\
\text { to } 2.20)\end{array}$ & & & $\begin{array}{c}0.10(-1.99 \text { to } \\
2.19)\end{array}$ \\
\hline $\begin{array}{l}\text { Bachelor's } \\
\text { degree }\end{array}$ & $214(59.9)$ & & & $\begin{array}{c}-0.87(-2.84 \\
\text { to } 1.11)\end{array}$ & & & $\begin{array}{c}0.05(-2.35 \text { to } \\
2.44)\end{array}$ & & & $\begin{array}{c}0.31(-1.77 \text { to } \\
2.40)\end{array}$ \\
\hline $\begin{array}{l}\text { Master's } \\
\text { degree }\end{array}$ & $9(2.5)$ & & & $\begin{array}{c}-0.70(-2.78 \\
\text { to } 1.37)\end{array}$ & & & $\begin{array}{c}0.01(-2.52 \text { to } \\
2.52)\end{array}$ & & & $\begin{array}{c}0.32(-1.87 \text { to } \\
2.51)\end{array}$ \\
\hline Doctorate & $1(0.3)$ & & & Reference & & & Reference & & & Reference \\
\hline
\end{tabular}

*** $p<0.01, * * p<0.05, * p<0.1$

Table 1. Continued. 


\begin{tabular}{|c|c|c|c|c|c|c|c|c|c|c|}
\hline \multirow[t]{2}{*}{ Variable } & \multirow[t]{2}{*}{$\mathbf{N}(\%)$} & \multicolumn{3}{|c|}{ Prevention ability } & \multicolumn{3}{|c|}{ Preparation ability } & \multicolumn{3}{|c|}{ Coping ability } \\
\hline & & $\mathrm{R}^{2}$ & $\mathrm{AR}^{2}$ & B (95\% CI) & $\mathrm{R}^{2}$ & $\mathrm{AR}^{2}$ & B (95\% CI) & $\mathrm{R}^{2}$ & $\mathrm{AR}^{2}$ & B (95\% CI) \\
\hline \multicolumn{11}{|l|}{ Position } \\
\hline Clinician & $85(23.8)$ & \multirow{4}{*}{0.019} & \multirow{4}{*}{0.011} & $0.13(-0.23$ to & \multirow{4}{*}{0.043} & \multirow{4}{*}{0.035} & $-0.03(-0.44$ to & \multirow{4}{*}{0.034} & \multirow{4}{*}{0.025} & $0.22(-0.14$ to \\
\hline $\begin{array}{l}\text { Clinical } \\
\text { nurse }\end{array}$ & $216(60.5)$ & & & $\begin{array}{c}0.48) \\
-0.20(-0.51 \\
\text { to } 0.11)\end{array}$ & & & $\begin{array}{c}0.39) \\
-0.45^{* *}(-0.82 \\
\text { to }-0.09)\end{array}$ & & & $\begin{array}{c}0.59) \\
-0.06(-0.38 \text { to } \\
0.26)\end{array}$ \\
\hline Clinicist & $4(1.1)$ & & & $\begin{array}{c}-0.08(-1.12 \\
\text { to } 0.97)\end{array}$ & & & $\begin{array}{c}-1.62^{* *}(-2.84 \\
\text { to }-0.39)\end{array}$ & & & $\begin{array}{c}-1.46^{* * *}(-2.53 \\
\text { to }-0.38)\end{array}$ \\
\hline Others & $52(14.6)$ & & & Reference & & & Reference & & & Reference \\
\hline \multicolumn{11}{|c|}{ Were you a member of frontline medical staff in the COVID-19 Pandemic? } \\
\hline Yes & $156(43.7)$ & 0.026 & 0.023 & $\begin{array}{c}0.33^{* * *}(0.12 \\
\text { to } 0.55)\end{array}$ & 0.025 & 0.022 & $\begin{array}{c}0.39 * * *(0.14 \text { to } \\
0.64)\end{array}$ & 0.040 & 0.037 & $\begin{array}{c}0.43^{* * *}(0.21 \text { to } \\
0.65)\end{array}$ \\
\hline No & $201(56.3)$ & & & Reference & & & Reference & & & Reference \\
\hline \multicolumn{11}{|l|}{ Region } \\
\hline $\begin{array}{l}\text { Shaanxi } \\
\text { Province }\end{array}$ & $197(55.2)$ & \multirow[t]{3}{*}{0.031} & \multirow[t]{3}{*}{0.026} & $\begin{array}{l}0.34^{* *}(0.08 \\
\text { to } 0.60)\end{array}$ & \multirow[t]{3}{*}{0.023} & \multirow[t]{3}{*}{0.017} & $\begin{array}{c}-0.11(-0.42 \text { to } \\
0.21)\end{array}$ & \multirow[t]{3}{*}{0.012} & \multirow[t]{3}{*}{0.006} & $\begin{array}{c}0.07(-0.21 \text { to } \\
0.34)\end{array}$ \\
\hline $\begin{array}{l}\text { Hubei } \\
\text { Province }\end{array}$ & $78(21.9)$ & & & $\begin{array}{c}0.53^{* * *}(0.21 \\
\text { to } 0.85)\end{array}$ & & & $\begin{array}{c}0.36^{*}(-0.02 \text { to } \\
0.73)\end{array}$ & & & $\begin{array}{c}0.32 *(-0.01 \text { to } \\
0.65)\end{array}$ \\
\hline $\begin{array}{l}\text { Yunnan } \\
\text { Province }\end{array}$ & $82(22.9)$ & & & Reference & & & Reference & & & Reference \\
\hline \multicolumn{11}{|l|}{$\begin{array}{l}\text { Hospital } \\
\text { grade }\end{array}$} \\
\hline $\begin{array}{l}\text { Tertiary } \\
\text { hospital }\end{array}$ & $29(8.1)$ & \multirow[t]{3}{*}{0.009} & \multirow[t]{3}{*}{0.003} & $\begin{array}{c}-0.19(-1.04 \\
\text { to } 0.66)\end{array}$ & \multirow[t]{3}{*}{0.005} & \multirow[t]{3}{*}{-0.001} & $\begin{array}{c}-0.01(-1.02 \text { to } \\
1.01)\end{array}$ & \multirow[t]{3}{*}{0.007} & \multirow[t]{3}{*}{0.001} & $\begin{array}{c}-0.03(-0.91 \text { to } \\
0.85)\end{array}$ \\
\hline $\begin{array}{l}\text { Secondary } \\
\text { hospital }\end{array}$ & $321(89.9)$ & & & $\begin{array}{c}0.16(-0.61 \text { to } \\
0.93)\end{array}$ & & & $\begin{array}{c}0.28(-0.64 \text { to } \\
1.20)\end{array}$ & & & $\begin{array}{c}0.27(-0.53 \text { to } \\
1.07)\end{array}$ \\
\hline Others & $7(3.0)$ & & & Reference & & & Reference & & & Reference \\
\hline
\end{tabular}

*** $p<0.01, * * p<0.05, * p<0.1$

Table 2. Relationship between the emergency capacity and participation of medical staff in pandemic prevention

\begin{tabular}{ccccc} 
Dimension & $\begin{array}{c}\text { Frontline medical staff in pandemic } \\
\text { prevention }(\mathrm{n}=156)\end{array}$ & $\begin{array}{c}\text { Not frontline medical staff in pandemic } \\
\text { prevention }(\mathrm{n}=\mathbf{2 0 1})\end{array}$ & $\begin{array}{c}\text { P- } \\
\text { value }\end{array}$ \\
\hline $\begin{array}{c}\text { Prevention } \\
\text { ability }\end{array}$ & $18.51 \pm 2.61$ & $17.51 \pm 3.35$ & 9.44 & 0.0023 \\
$\begin{array}{c}\text { Preparation } \\
\text { ability }\end{array}$ & $31.96 \pm 6.50$ & $29.62 \pm 7.79$ & 9.14 & 0.0027 \\
$\begin{array}{c}\text { oping } \\
\text { ability }\end{array}$ & $161.96 \pm 24.30$ & $150.01 \pm 32.60$ & 14.65 & 0.0002 \\
\hline
\end{tabular}

Table 3. Relationship between emergency capacity and the region of medical staff

\begin{tabular}{|c|c|c|c|c|c|}
\hline Dimension & $\begin{array}{c}\text { Shaanxi Province }(\mathrm{n}= \\
197)\end{array}$ & $\begin{array}{c}\text { Hubei Province }(\mathrm{n}= \\
78)\end{array}$ & $\begin{array}{c}\text { Yunnan Province }(\mathrm{n}= \\
82)\end{array}$ & $\mathrm{F}$ & $\begin{array}{c}\mathrm{P}- \\
\text { value }\end{array}$ \\
\hline Prevention ability & $18.06 \pm 3.09$ & $18.63 \pm 2.30$ & $17.04 \pm 3.53$ & 5.74 & 0.0035 \\
\hline $\begin{array}{l}\text { Preparation } \\
\text { ability }\end{array}$ & $29.89 \pm 8.06$ & $32.67 \pm 5.58$ & $30.52 \pm 6.67$ & 4.08 & 0.0178 \\
\hline Coping ability & $154.10 \pm 30.89$ & $161.23 \pm 24.39$ & $152.24 \pm 31.42$ & 2.15 & 0.1186 \\
\hline
\end{tabular}

Table 4. Correlation between emergency capacity and self-efficacy of medical staff

\begin{tabular}{lllll}
\hline & Prevention ability & Preparation ability & Coping ability & Self-efficacy \\
\hline Prevention ability & 1.0000 & & & \\
Preparation ability & $0.5981^{*}$ & 1.0000 & & \\
& 0.0000 & & & \\
Coping ability & $0.6266^{*}$ & $0.7608^{*}$ & & \\
& 0.0000 & 0.0000 & & \\
Self-efficacy & $0.2017^{*}$ & $0.3576^{*}$ & $0.3759^{*}$ & 1.0000 \\
& 0.0001 & 0.0000 & 0.0000 & \\
\hline
\end{tabular}


* shows significance at the 0.05 level

\section{Figures}

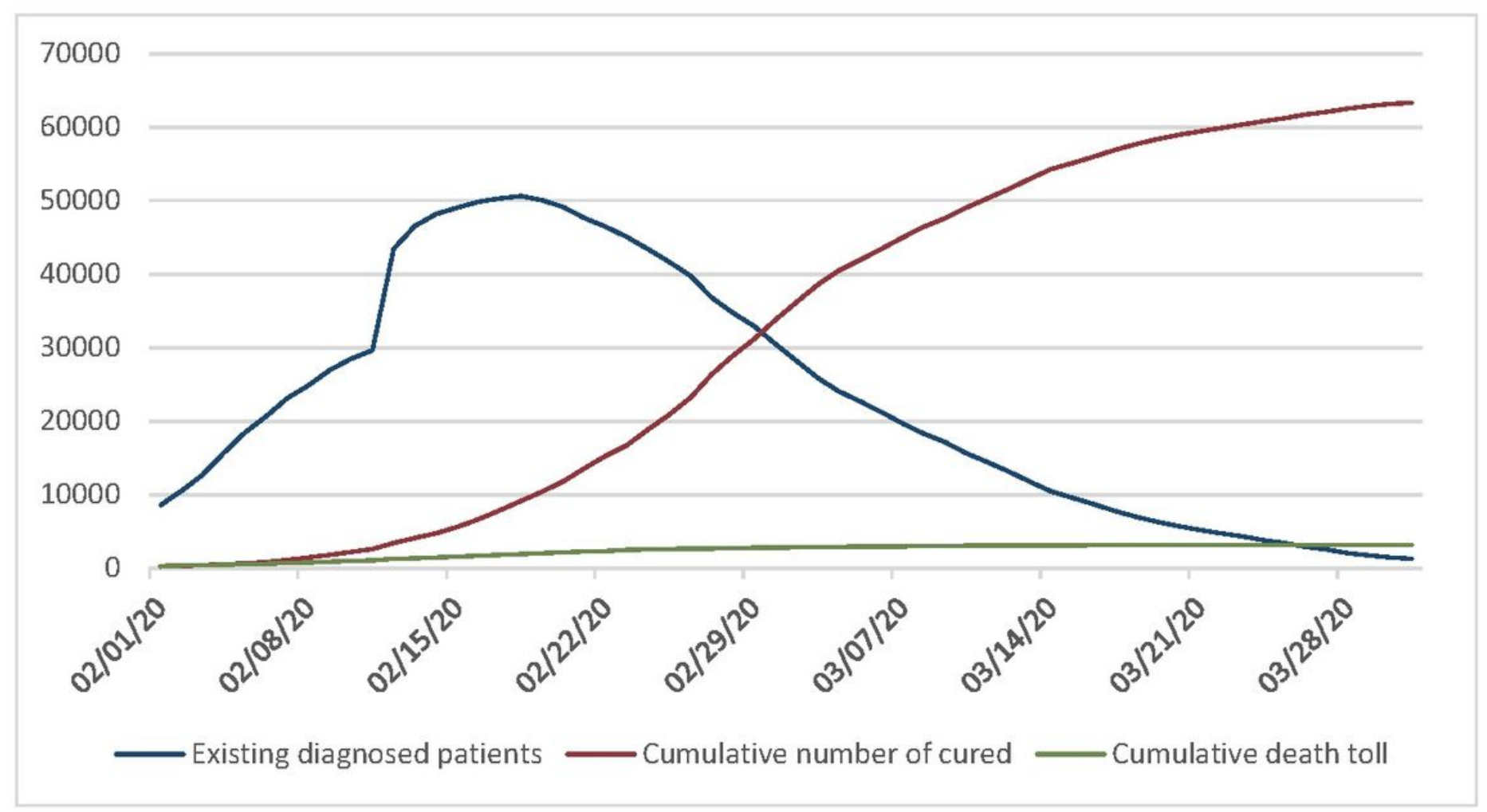

Figure 1

Changes in the number of existing diagnosed patients, cumulative number of cured patients, and cumulative death toll in Hubei, China from February to March 2020

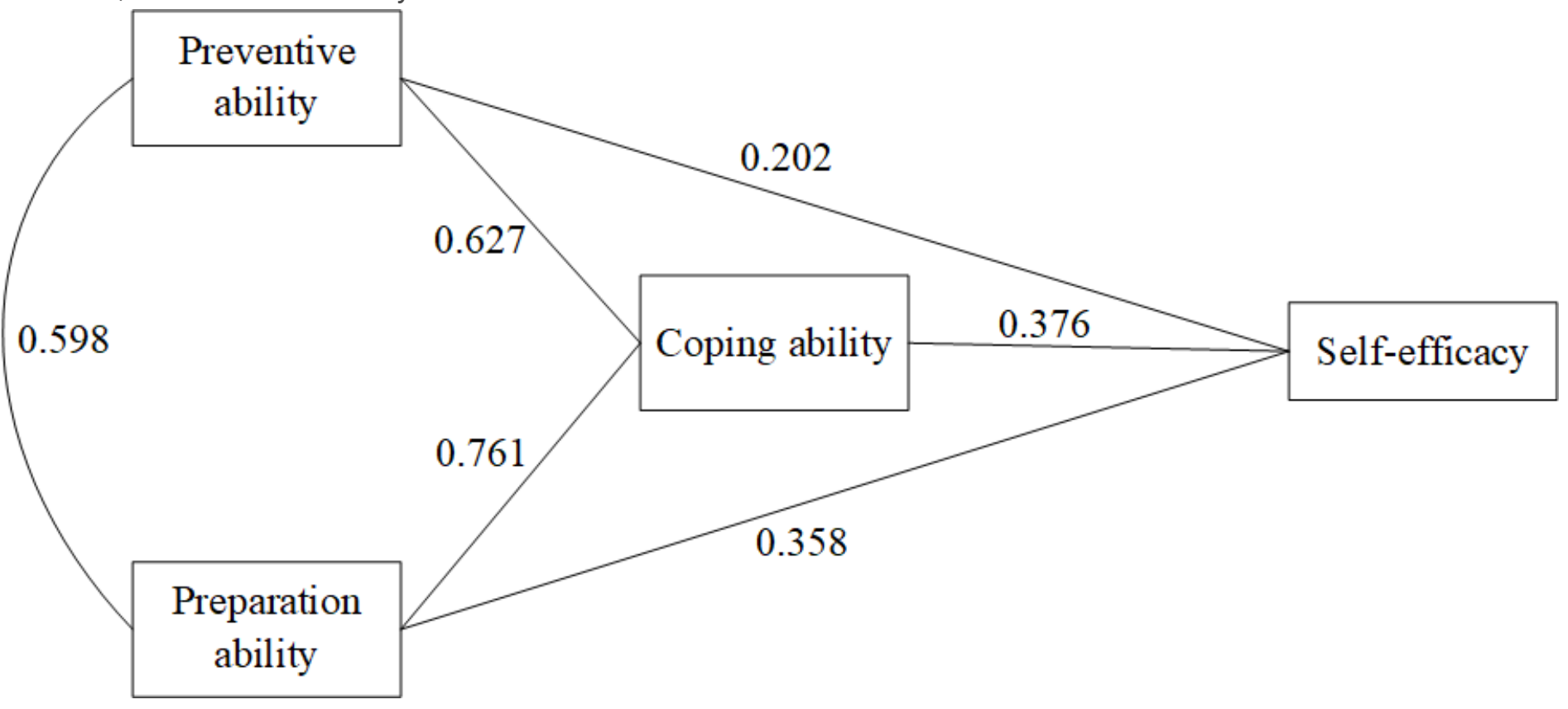

Figure 2 
Pearson's Correlations Between Emergency Capacity and Self-efficacy of Medical Staff

\section{Supplementary Files}

This is a list of supplementary files associated with this preprint. Click to download.

- Hubei.xlsx

- Data.dta

- EPIQ.docx 